Session 1375

\title{
Course Syllabus Construction: A Stitch in Time Saves Nine
}

\author{
Dr. Paul Blowers \\ Department of Chemical and Environmental Engineering \\ The University of Arizona
}

\begin{abstract}
Young faculty are often challenged by the wide variety of demands that are placed on their time, especially in their first several years as they learn how to function in their new work environment. Oftentimes, younger faculty may try to cut corners when preparing for the first courses that they teach. This talk addresses syllabus construction and how a well-planned syllabus can lead to a class that runs smoothly throughout the entire semester.

Careful preparation of a course syllabus can help young faculty in many ways. A complete syllabus with clear guidelines alleviates student anxiety and shows the students that you care about the course. A complete syllabus also allows you to focus on your lesson plans during the semester instead of having to deal with developing course policies on the fly. A comprehensive syllabus gives you a document to rely on when student concerns or conflicts arise. Many institutions, in fact, prevent course policies from being changed once they are made available to students on the syllabus.
\end{abstract}

There are several key elements that must be in a course syllabus. These elements include contact information for the instructor and TA. Office hours should be set and included in the syllabus if possible. Course policies about late homework, missed exams, and illnesses should also be clearly stated. Guidelines on suitable homework formats are very useful for students as they try to improve their skills.

Other elements of a good syllabus are often overlooked by faculty. One particularly useful section to include is a list of all course objectives for the semester. This gives you concise guidelines on how to select your exam questions and homework assignments. If you don't have a homework or exam question on a listed objective, then you should rethink your objectives. From a student perspective, students also appreciate listings of test dates, homework due dates, and grading criteria related to the final grading scale.

\section{Introduction}

Syllabi serve many functions to different groups of users. Students view a syllabus as a contract $^{1-5}$ with the professor that describes how they should behave, what the class schedule is, and how they need to perform in order to receive a passing grade. Faculty use the syllabus to organize their thoughts about the course, to outline course content, and to inform students in the class what is expected of them ${ }^{6}$. Surprisingly, though, many professors do not take advantage of 
their syllabi to accomplish these goals. Figure 1 shows a syllabus from a recent course that has been modified only in that it was changed to make it anonymous.

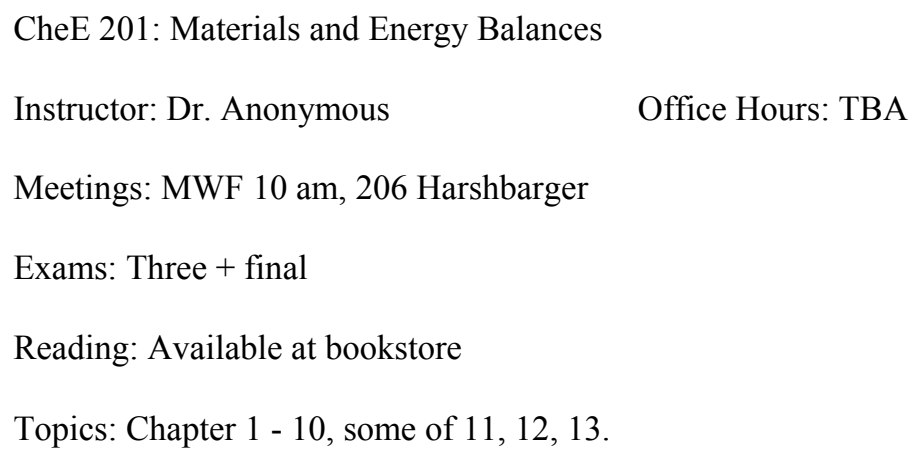

Figure 1 - A sample resume from a course taught last year. This syllabus has been changed so that it is now anonymous. All other content was left unchanged.
This syllabus has the minimum amount of content for it to actually be called a syllabus. You can see that the professor made little effort to convey any useful information to the students and that the students have very little guidance about how the course will be run. The students probably already knew what the course was called and when it was

meeting. However, more information about the reading assignments and chosen texts is needed. Also, more defined grading criteria are called for in addition to a better description of the topics that will be covered in the class.

Several students communicated comments to the author about the class using the syllabus shown in Figure 1. Students expressed frustration clear guidelines were never given about how their final grades would be determined. They were particularly frustrated because the minimal information from the syllabus was not adhered to as there were only two exams and a final instead of three exams and a final. Students viewed the professor as incompetent and uncaring because of the little effort demonstrated through their initial contact with the professor.

Clearly there must be more in a syllabus to engage students ${ }^{7-8}$. The syllabus is the first hand-out that students will receive in a course and they will refer to it throughout the semester ${ }^{2,8}$ as they apportion their efforts among their obligations. A more complete syllabus that communicates information clearly will aid students in studying and eliminate many conflicts later on during the semester. Eliminating potential conflicts and student anxieties will certainly save extra effort for the professor later on ${ }^{9}$.

\section{How a Well Designed Syllabus Can Aid the Professor}

So far, it seems like a well constructed syllabus is good only for the students because it delineates the professor's expectations for them. There are three major areas of a syllabus that can greatly aid the professor throughout the semester. These three areas involve course objectives, grading policies, and format for student assignments. The usefulness of clear course objectives will be discussed first.

The creation of a list of objectives that describe what students must be able to do upon completion of the course is an extremely useful exercise for faculty before the first day of class ${ }^{10-}$ 
12. This list should be a series of statements that describe what a student should be able to do, when they should do it, and how it fits within the context of the course as shown in Figure 2. These statements focus the course so that it becomes a coherent series of lectures instead of being a loosely related series of topics. Simply listing topics as some advocate ${ }^{9}$ is not as useful as listing objectives that involve successful actions by the students.

A complete list of objectives makes it easier to construct good tests that assess student learning in a course. Exams are normally timed in-class activities that can only cover a finite amount of material. A focused list of objectives allows the professor to select the most important information to include on the exam. Also, the list can be used by the professor to create multiobjective questions that test students' depth of understanding in whether they are integrating their knowledge into a flexible problem solving framework. These types of multi-objective test questions are very good indicators of student progress towards mastering complex material.

Well constructed syllabi can save extra effort on the professor's part if they include:

- well written course objectives

- a clear grading policy

- and, formatting instructions for student assignments.

Figure 3 - The three major areas that save professor time when they are included on a syllabus.

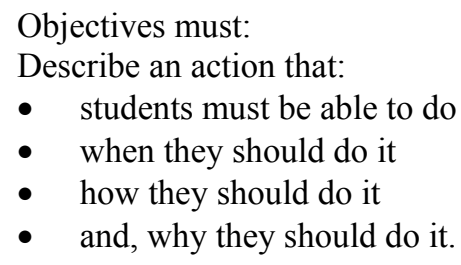

Figure 2 - A description of what must be included in a good course objective.

The second major area shown in Figure 3 where a clear syllabus can aid a professor is having a clear grading policy. Listing a clear and complete guideline for student assessment forces the professor to pick a grading policy and then stick with it throughout the semester. It also allows the professor to refer to the written syllabus when students come in with complaints. When it is clear the written syllabus will be followed, students will not waste time attempting to lobby the professor for special circumstances. The amount of time that can be saved by having a clear grading policy in the syllabus cannot be underestimated because many students will be preoccupied by their grade in the class.

One quick note about grading should be made at this point. The author strongly advocates moving the class to a straight grading scale and this is the subject of another paper ${ }^{13}$. A straight scale will remove competition from the classroom and make it easier for us to achieve ABET accreditation on topics like teamwork and communication skills. It will also allow 
students to focus on the material and learning it instead of focusing on each other and how to do better against a curved grading scale.

Finally, having a complete description of the format expected on student assignments can also eliminate many student complaints. Format descriptions should include any special requirements like paper type, neatness, documentation of references, and other specialized information you wish the students to know. Setting high expectations will demonstrate to students the level of professionalism that you will be expecting from them and will support you in your comments on the students' work later during the semester. It is particularly important students receive feedback on the first few assignments and are reminded of the written criteria in the syllabus. If students are not reminded of the requirements, they will normally continue to submit work that is substandard with regards to format.

\section{The Information that Should be on a Course Syllabus}

We've already seen a very poor syllabus in Figure 1 that was recently used in an engineering course. Even this minimal syllabus had some of the elements that a well constructed syllabus should have. We will now discuss the elements of a complete syllabus.

The syllabus must contain complete contact information for the course. The contact information should include the professor's name, office, phone number, email address, and how students should contact them in case of an emergency. Some also advocate giving out home telephone numbers ${ }^{3,6}$, but that is left to the professor's own opinion. If there is a special contact person on staff for the class, like a technical assistant, teaching assistant, or secretary, their contact information should also be included. Staff information should be cleared with them prior to inclusion on the syllabus to ensure they have listed only the information they desire.

Information about the locations and

\begin{tabular}{|l|}
\hline \multicolumn{1}{|c|}{ Syllabus Information } \\
Contact information + staff information \\
Office hour times and locations \\
Course information \\
Text information \\
List of course objectives \\
Grading criteria and scale \\
Class schedule \\
Assignment formatting instructions \\
Other
\end{tabular}

Figure 4 - Information that should be included on a complete syllabus. Laying this information out saves professor effort later. times of office hours should also be listed on the syllabus. It is common, though, to list that office hours will be determined. If this is done, one should set office hours as early as possible in the semester and then distribute a handout with that information so students can include it in their syllabus.

This paper already discussed how clear course objectives, a written grading policy, and expectations on the format of student assignments can save effort during the semester. More general topics like a description of the course and the text can also be added. Scheduling information is also very useful for both the professor and the students throughout the semester. Additional information like offers of assistance for outside help can also aid some students ${ }^{14}$. 
The author was fortunate to have an extremely organized professor as their first instructor in engineering. This instructor had a complete timeline for the entire semester listed on the syllabus which described when exams would be given, the problems assigned each day, and the sections of the book covered in lecture each day. This list was extremely useful to students in the class since they were able to plan their days and weeks according to the master schedule. It was particularly useful because the students could work ahead on the homework on weeks when they had many exams ${ }^{15}$. Because it was so useful to the students, it is advocated by this author for all syllabi. For an example of a complete syllabi, the website at: http://www.che.arizona.edu/Directory/Faculty/Blowers/chee_201.htm has more information.

\section{Students and the Syllabus}

We've already seen how a complete syllabus can reduce student complaints and uncertainties throughout the semester. Students often review the syllabus to make sure they understand the course guidelines and how they are being assessed on their assignments. Because the students refer to the syllabus so often, many of them will view it as a contract and will use it to know what is expected from them and what they can expect from you as the professor.

At some schools, changes in syllabus information once the course begins is not allowed. Students who are affected by a change in the syllabus later in the semester have a course of action they can pursue to prevent this from happening. This recourse is available because faculty sometimes attempt to modify the syllabus late in the semester and penalize some students through that change. This is commonly encountered when an exam is dropped, the final is no longer given, or the grade weighting is changed among the assignments.

Students made the following specific comments about the syllabus used in our introductory chemical engineering course at the University of Arizona:

- "I liked having the complete schedule since it helped me plan my weeks better."

- "The best parts were the objectives. I wouldn't have known what to study without them."

- "Why doesn't the University have a policy on making syllabuses more uniform?"

The students here benefited from a complete syllabus that clearly laid out the expectations that would be asked of them throughout the semester. They referred to the syllabus throughout the semester for many of the little questions they had about how the class would be run. Also, they did not complain about the workload even though it is a very high workload in an introductory class because they were able to work around time conflicts though a complete schedule.

\section{Conclusions}

Laying out expectations for the students eliminates many problems throughout the semester. The clear guidelines encourage the students to plan ahead and to work diligently. Having clear course objectives lets them know what material will be emphasized and helps the professor write better exams to assess student knowledge. A clear grading policy also puts 
students at ease and lets them know what to do to succeed in the course. A syllabus is the perfect opportunity to provide all this information to students so they can achieve success in their classes. A complete syllabus also benefits the professor by reducing complaints and by focussing the lecture and exam materials on the important topics.

\section{References:}

1. Baker, R. N., "The mathematics syllabus and adult learners in community colleges" Integrating technique with content", Comm. Coll. J. Res. Pract., 25, 391-402 (2001).

2. Smith, M. F., and N. Y. Razzouk, "Improving Classroom Communication: The Case of the Course Syllabus", $J$. Educ. for Bus., March/April, 215-221 (1993).

3. Matejka, K. and L. B. Kurke, "Designing a Great Syllabus", Coll. Teach., 42, 115-117 (1994).

4. Eberly, M. B., S. E. Newton, and R. A. Wiggins, "The Syllabus as a Tool for Student-Centered Learning", J. Gen. Ed., 50, 56-74 (2001).

5. Becker, A. H., and S. K. Calhoon, "What Introductory Psychology Students Attend to on a Course Syllabus", Teaching of Psychol., 26, 6-11 (1999).

6. Wankat, P. C., and F. S. Oreovicz, "Chart your course", ASEE Prism, 8, 18 (1999).

7. Behnke, R. R., and P. Miller, "Information in class syllabus may build student interest", Educator, 45-47 (1989).

8. Smith, R. M., "Essential ethical considerations in education", Education, 117, 17-21 (1996).

9. Hockensmith, S. F., "The Syllabus as a Teaching Tool", Educ. Forum, 52, 339-351 (1988).

10. McIntosh, W. J., "The Expanded Syllabus as an Aid for the Underprepared Science Student", J. Coll. Sci.

Teach., 137-138, November (1987).

11. Brent, R., and R. M. Felder, "It's a start", College Teaching, 47, 14-17 (1999).

12. Finelli, C. J., A. Klinger, and D. D. Budny, "Strategies for Improving the Classroom Environment", J. Engr. Educ., 90, 491-497 (2001).

13. Blowers, P., "Breaking the Curve - Why a Straight-Scale is Apopropriate in Engineering Courses", Proceedings of the 2002 American Society for Engineering Education Annual Conference and Exposition.

14. Perrine, R. M., J. Lisle, and D. L. Tucker, "Effects of a Syllabus Offer of Help, Student Age, and Class Size on College Students' Willingness to Seek Support From Faculty", J. Exp. Educ., 64, 41-52 (1995).

15. Kleen, B. A., "Detailed course syllabus aids methods students", Bus. Educ. Forum, March, 31-34 (1985).

\section{PAUL BLOWERS}

Paul Blowers is an Assistant Professor in the Department of Chemical and Environmental Engineering at the University of Arizona. He received his B.S. in Chemical Engineering from Michigan State University before attending the University of Illinois at Urbana-Champaign for his M.S. and Ph.D. in Chemical Engineering. In addition to educational research, his other academic research involves using quantum chemical techniques for predicting reaction rates in different environments. 